JKAU: Comp. Sci., Vol. 5, pp: 83 - 92 (2016 A.D. / 1437 A.H.)

DOI: 10.4197 / Comp. 5 - 6

\title{
A Fuzzy Controlled Image Watermarking Based on a Dual Transform Technique
}

\author{
Bander Albarakati, Abdullah Basuhail, Gibrael Abo Samra \\ Faculty of Computing and Information Technology \\ King Abdulaziz University, Jeddah, Saudi Arabia \\ abasuhail@kau.edu.sa,gabosamra@kau.edu.sa
}

\begin{abstract}
This paper presents a new watermarking technique using hybrid image transforms that aims to be very robust against attacks. It also aims to reduce the amount of distortion created from embedding the watermark as much as possible, and have good capacity. The proposed system uses a hybrid watermarking technique that is based on Non-Subsampled Contourlet Transform and Discrete Wavelet Transform. In addition, the proposed system makes use of the fuzzy logic to automatically choose the strength of the embedded watermark. Furthermore, the system uses Spread Spectrum Code Division Multiple Access to embed and recover the watermark after transforming the image. To enhance recoverability of the watermarks, the system uses a high level of redundancy in the embedding process, which allows a powerful Error Correcting Code to be used in the recovery process. The fuzzy logic is used to help the system in producing watermarked images that reserve their quality and not be heavily altered after embedding the watermark. Experiments were performed to measure the quality of the proposed system using JPEG compression attacks. The results showed that the proposed system is robust and has good capacity and imperceptibly although it suffers from being computationally complex.

Index Terms-Watermarking, Image processing, Discrete wavelet transforms, Nonsubsampled contourlet transforms, Fuzzy Logic, Error Correction Codes, Spread Spectrum.
\end{abstract}

\section{Introduction}

WATERMARKING for online protection of people's work is more important now than ever, especially with the amount of multimedia being created, sold or shared on the internet. It is also used as a technique to embed metadata more robustly into files. Watermarks are seen on TV channels and in newspapers for protecting the copyright of videos and images. They are also used by news websites to mark and protect their posted exclusive pictures, and on many photography websites to mark and protect the photographers' ownership.

Every watermarking system has some good features and lacks others. Any watermarking technique has specific properties depending on what the technique is made for. For instance, some techniques produce fragile watermarks that are easily removed or corrupted, such watermarks are made to be embedded into images as a proof that the image is authentic and that no one has altered or manipulated the image.

The system proposed in this paper provides a way to embed and recover watermarks from images while being robust against attacks, and imperceptible. The system uses Non-Subsampled Contourlet Transform (NSCT) and has an error correction code to recover and fix the recovered watermark and also to speed up the embedding process instead of embedding in one subband which will require higher embedding strength to be used. The system uses fuzzy logic to adaptively select the optimal strength used in the embedding process. This is to avoid using very high embedding strength that might introduce noise to the watermarked image and make it simple to use 
without the need for adjustment with each used image.

\section{Overview of the watermarking system}

The proposed system embeds the watermarks using Spread Spectrum Code Division Multiple Access (SS-CDMA) after transforming the image using NSCT then Discrete Wavelet Transform (DWT). The system uses NSCT-DWT and SSCDMA again to recover the watermarks. The system utilizes Fuzzy Logic to improve its robustness, imperceptibility and ease of use.

The proposed scheme embeds in Level 3 and Level 4 NSCT subbands. These subbands, the error correction code and the implemented fuzzy logic all are used to achieve imperceptibility as much as possible in the process of watermarking while preserving the system's robustness. The Contourlet Transform (CT) with Spread Spectrum was used in [1] and gave better results than DWT with CDMA. We chose NSCT to be used in our system with CDMA since in [2] the researchers found after comparing CT and NSCT that NSCT is better for watermarking applications than CT when focusing on imperceptibility and robustness NSCT is more complicated and uses more time than CT [2].Our technique has a loop that its counter can be set. The system also allows the user to set a specific PSNR value that the system will stop at whether the watermark is fully embedded or not as shown in Figure1. To implement NSCT as defined in [3], we used the NSCT implementation in [4].

\section{Embedding using NSCT-DWT based system}

The proposed system, as shown in Figure 1, starts the embedding process by transforming the host image using NSCT to 4 Levels (1, 2, 3 and 4). Then all the produced subbands from all the levels are left intact except the subbands at Level 3 and Level 4 NSCT that are transformed using Level 1 DWT. Figure 1 shows the embedding process of the proposed system. Figure 2 shows the regions that are used, which are Level 1 DWT's LL and LH. These two regions of DWT are used with a secret key to embed the watermark using SSCDMA. The recovering process is similar to the embedding process except that these two regions of DWT from every used subband are used with the secret key to recover the embedded watermark. The system will recover a number of replicas of the embedded watermark which were embedded in the subbands. All recovered replicas will be fed to the error correction code to correct them and then produce one corrected watermark. The system calculates the Peak Signal-to-Noise Ratio (PSNR) of the watermarked image and the Normalized Cross-correlation (NC) of the recovered and corrected watermark. Based on the values of PSNR, NC and the user's inputs, the system decides whether to release the watermarked image or to re-embed the watermark again using a different embedding strength which will be chosen by the fuzzy logic. The error correction code and the implemented fuzzy logic in the proposed scheme will be explained in this paper in later sections. The inputs to the system are the host image, binary watermark, key for the SS-CDMA, limit for the loop's counter, initial embedding strength and limit for the acceptable watermarked image's PSNR as shown in Figure 1.

We tested the proposed system with and without Level 1 DWT. The results listed in Table I show that both cases produced watermarked images with almost similar PSNRs, but the system with Level 1 DWT fully recovered more watermarks than the system without Level 1 DWT.

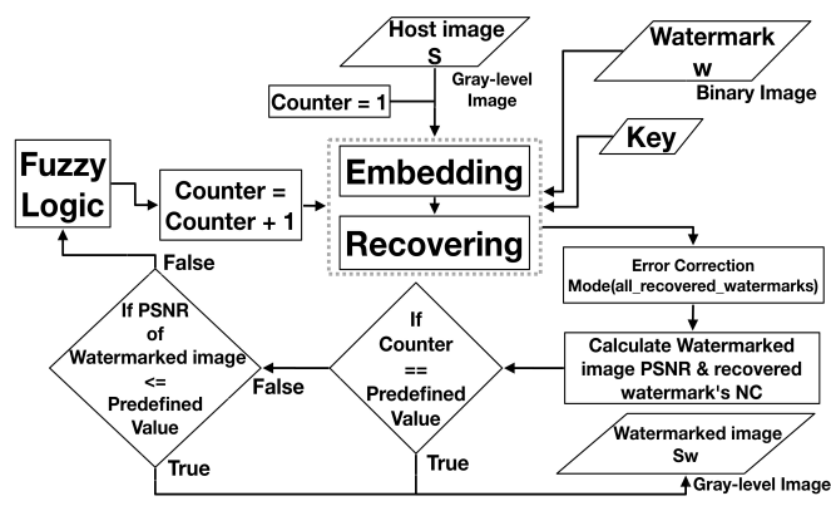

Fig. 1. Embedding using the NSCT-DWT technique. 


\section{Recovering using the NSCT- DWT based system}

To recover a watermark, first the watermarked image is transformed using NSCT and then using DWT in a similar way to that performed in the embedding process. After extracting the regions used to embed the watermark in Level 1 DWT, the scheme will recover the embedded watermark using SS-CDMA using the key. The recovered replicas of the watermark embedded in the used NSCT subbands will be fed to the Error Correction Code to be corrected in order to recover one watermark that is error free, as much as possible. The process of recovering watermarks in our proposed system is shown in Figure 3.

TABLE I.COMPARISON BETWEEN OUR SYSTEM WITH LEVEL 1 DWT (HYBRID) AND WITHOUT LEVEL 1 DWT (NON-HYBRID)

\begin{tabular}{|c|c|c|}
\hline \multicolumn{3}{|c|}{ PSNRs of the watermarked images } \\
\hline Image & Non-Hybrid $(\mathrm{dB})$ & Hybrid $(\mathrm{dB})$ \\
\hline Peppers & 33.91 & 33.99 \\
\hline Airplane (F-16) & 33.90 & 33.98 \\
\hline Pentagon & 33.92 & 34.00 \\
\hline Boat & 33.91 & 33.99 \\
\hline Tank & 33.91 & 33.99 \\
\hline \multicolumn{3}{|c|}{ Embedding Strength using fuzzy logic } \\
\hline Image & Non-Hybrid & Hybrid \\
\hline Peppers & 0.27 & 0.31 \\
\hline Airplane (F-16) & 0.27 & 0.31 \\
\hline Pentagon & 0.27 & 0.31 \\
\hline Boat & 0.27 & 0.31 \\
\hline Tank & 0.27 & 0.31 \\
\hline \multicolumn{3}{|c|}{ Number of iterations to embed the watermark } \\
\hline Image & Non-Hybrid & Hybrid \\
\hline Peppers & 3 & 4 \\
\hline Airplane (F-16) & 3 & 4 \\
\hline Pentagon & 3 & 4 \\
\hline Boat & 3 & 4 \\
\hline Tank & 3 & 4 \\
\hline \multicolumn{3}{|c|}{$\begin{array}{c}\text { Number of fully recovered watermarks after JPEG compressior } \\
\text { attacks }(Q F=10,20,30,40,50,60,70,80 \text { and } 90)\end{array}$} \\
\hline Image & Non-Hybrid & Hybrid \\
\hline Peppers & 7 & 7 \\
\hline Airplane (F-16) & 3 & 6 \\
\hline Pentagon & 6 & 6 \\
\hline Boat & 3 & 6 \\
\hline Tank & 6 & 8 \\
\hline
\end{tabular}

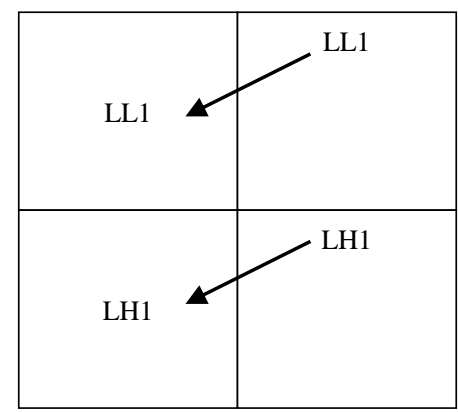

Fig. 2. Regions of embedding and recovering in (L-1) DWT.

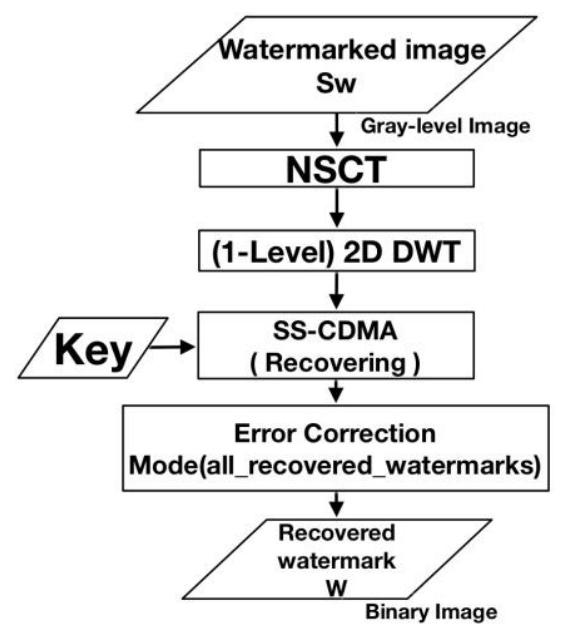

Fig. 3. Recovering using NSCT- DWT.

\section{Implemented Error Correction Code for NSCT Subbands}

The error correction code implemented in the proposed system gathers all the recovered watermarks that are embedded in the used NSCT subbands. We embedded a watermark and then extracted the recovered data before and after the correction process as shown in Table II.

TABLE II. WATERMARK BEFORE AND AFTER BEING COLLECTED BY THE ERROR CORRECTION CODE

\begin{tabular}{ccc}
\hline \hline $\begin{array}{c}\text { Original } \\
\text { watermark }\end{array}$ & $\begin{array}{c}\text { Replicas of uncorrected } \\
\text { recovered watermarks }\end{array}$ & $\begin{array}{c}\text { Corrected recovered } \\
\text { watermark }\end{array}$ \\
\hline & &
\end{tabular}




\section{ti1 \\ ill}

After gathering the embedded data, the code calculates the mode value of the pixels of the recovered watermarks. First, all the pixels in position $(1,1)$ of all the recovered watermarks are gathered and used in the calculation, then position $(1,2)$ until the last pixel of the recovered watermark as shown in Figure 4. The recovered data are in binary, so for every group of pixels, the group with the most "Ones" will result in a pixel with the value " 1 ", and the group with the most "Zeroes" will result in a pixel with the value " 0 ". We tested our system to embed and recover from 1 NSCT subband instead of using all subbands from 2 levels. We found that both of them produced watermarked images with almost similar PSNRs but the system that uses all subbands of Leve 3 and Level 4 of NSCT fully recovered more watermarks than the system that only uses 1 subband. We also noticed that the system that uses only 1 subband made iterations much more than the other system as shown in the results in Table III.

TABLE III.COMPARISON BETWEEN USING 1 SUBBAND AND USING ALL SUBBANDS

\begin{tabular}{|c|c|c|}
\hline \multicolumn{3}{|c|}{ PSNRs of the watermarked images } \\
\hline Image & $\begin{array}{l}1 \text { Subband in } \\
\text { Level } 3 \text { NSCT }\end{array}$ & $\begin{array}{l}\text { all subbands in } \\
\text { Level } 3 \text { and Level } \\
4 \text { NSCT }\end{array}$ \\
\hline Peppers & $33.96 \mathrm{~dB}$ & $33.99 \mathrm{~dB}$ \\
\hline Airplane (F-16) & $33.97 \mathrm{~dB}$ & $33.98 \mathrm{~dB}$ \\
\hline Pentagon & $33.95 \mathrm{~dB}$ & $34.00 \mathrm{~dB}$ \\
\hline Boat & $33.98 \mathrm{~dB}$ & $33.99 \mathrm{~dB}$ \\
\hline Tank & $33.97 \mathrm{~dB}$ & $33.99 \mathrm{~dB}$ \\
\hline \multicolumn{3}{|c|}{ Embedding Strength chosen by the fuzzy logic } \\
\hline Image & 1 Subband & All subbands \\
\hline Peppers & 0.31 & 0.31 \\
\hline Airplane (F-16) & 0.32 & 0.31 \\
\hline Pentagon & 0.31 & 0.31 \\
\hline Boat & 0.32 & 0.31 \\
\hline Tank & 0.32 & 0.31 \\
\hline \multicolumn{3}{|c|}{ Number of loops to embed the watermark } \\
\hline Image & 1 Subband & All subbands \\
\hline Peppers & 42 & 4 \\
\hline Airplane (F-16) & 40 & 4 \\
\hline Pentagon & 42 & 4 \\
\hline Boat & 40 & 4 \\
\hline Tank & 40 & 4 \\
\hline \multicolumn{3}{|c|}{ Number of fully recovered watermarks after JPEG comp. attacks } \\
\hline Image & 1 Subband & All subbands \\
\hline
\end{tabular}

\begin{tabular}{|l|l|l|}
\hline Peppers & 2 & 7 \\
\hline Airplane (F-16) & 6 & 6 \\
\hline Pentagon & 8 & 6 \\
\hline Boat & 2 & 6 \\
\hline Tank & 7 & 8 \\
\hline
\end{tabular}

\section{SS-CDMA implementation}

The SS-CDMA used in the proposed system is same as in [5], where a Key, which is an array of numbers, is used with a pseudorandom number generator to randomly add numbers to specific parts of the image, whenever a 0 is found in the watermark. In the recovery process, the system goes to the embedding locations and calculates the correlation coefficient to determine the zeroes in the recovered watermark and then fill the rest with ones. To embed using SS-CDMA where LL and $\mathrm{LH}$ are the regions used for embedding and recovering in Level 1 DWT, wLL and $w L H$ are the same regions after being watermarked, $\mathrm{k}$ is the embedding strength that is given by the fuzzy module and "PN" are the pseudorandom numbers generated by the SS-CDMA. The values of wLL and wLH are computed as:

$$
\begin{aligned}
& w L L=L L+k \times P N \\
& w L H=L H+k \times P N
\end{aligned}
$$

Recovering the watermark is done as in [5], by iterating $\mathrm{n}$ times, where $\mathrm{n}$ equals the length of the watermark. For every iteration, the system uses a new PN with the Key. It then calculates the 2-D correlation coefficients between wLL and PN and wLH and PN, adds the two results together and divide them by 2 . Then for the whole length of watermark the system will add 0 s and replace every zero with a one whenever the correlation exceeds the threshold as mentioned in [5].
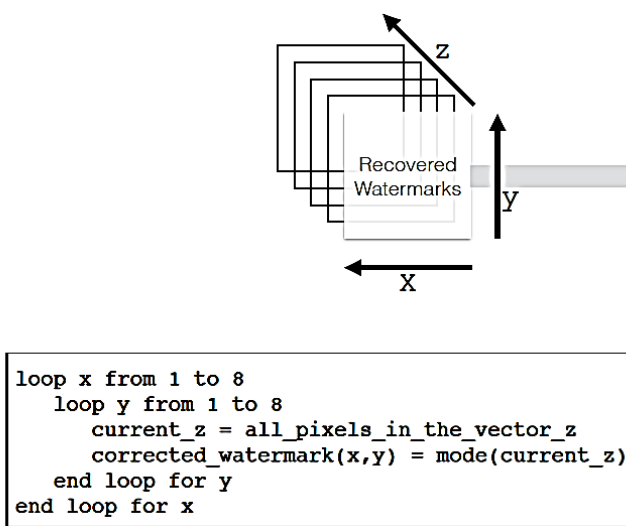
Fig. 4. Error correction code used on $8 \times 8$ watermarks.

\section{Utilization of Fuzzy Logic}

Fuzzy logic is used in our system mainly to enable it to automatically choose the embedding strength " $\mathrm{k}$ ", which is the value that determines the strength used in embedding the watermark. Using " $\mathrm{k}$ " with high value can make the system very robust, but adds noise to the watermarked image. Using " $k$ " with low value can leave the watermarked image looks almost untouched, but will produce a weak watermark that can be easily removed or corrupted. The value of " $k$ " is used in embedding as given previously in equation (1). Our technique starts by embedding a watermark with the user predefined value of $\mathrm{k}$. Then, after the first iteration, the system determines the Normalized Cross-correlation (NC) of the recovered watermark and the Peak Signal-toNoise Ratio (PSNR) of the watermarked image and feed them to the fuzzy module. The fuzzy module completes the task in the next iterations until the final watermarked image is produced. In every iteration, the system adds the current " $\mathrm{k}$ " value suggested by the fuzzy logic with the previous value of " $\mathrm{k}$ " used in the system cumulatively, and this is the reason of small kvalues in our implementation. The fuzzy logic implemented in our system has 2 inputs and 1 output. It receives the $\mathrm{NC}$ of the recovered watermarks and the PSNR of the watermarked image, and outputs the value of " $k$ ". To aggregate the final output, the system uses the "max" method that outputs the maximum value of the output crisp set chosen by the fuzzy system. For defuzzification, the "Centroid" method is used which outputs the value that is located in the center of the area under the curve. This fuzzy logic implementation has 2 input variables. The first variable for the received $\mathrm{NC}$ values has 2 membership functions. The first has the parameters $(0,0.3$ and 0.65$)$, and the second has $(0.4,0$, and 9.1). The second variable for the received PSNR has three membership functions with the parameters $(0,15,32.7),(20,35,44.97)$ and $(42,80,80)$. As shown here the input is set to 80 , yet it's unlikely that the image PSNR will be $80 \mathrm{~dB}$ after being watermarked although keeping the value 80 here won't affect the system's quality. For the output of the fuzzy logic system, the system has 1 variable which has 3 membership functions with the parameters $(0.002,0.005,0.01),(0.006,0.01,0.03499)$ and $(0.0298,0.038,0.05)$.

The membership functions in our system are shown in Figures 5-7. The rules in the fuzzy logic in our proposed system are as follows:

1) If (NC_of_recovered_watermark is "bad" and PSNR_or_watermarked_image is "bad") then Increase_strength_slowly.

2) If (NC_of_recovered_watermark is "bad" and PSNR_or_watermarked_image is "very bad")

then Increase_strength_moderately.

3) If (NC_of_recovered_watermark is "bad" and PSNR_or_watermarked_image is "good") then Increase_strength_fast.

4) If (NC_of_recovered_watermark is "good" and PSNR_or_watermarked_image is "very bad") then Increase_strength_slowly.

5) If (NC_of_recovered_watermark is "good" and PSNR_or_watermarked_image is "bad") then Increase_strength_moderately.

6) If (NC_of_recovered_watermark is "good" and PSNR_or_watermarked_image is "good") then Increase_strength_fast.

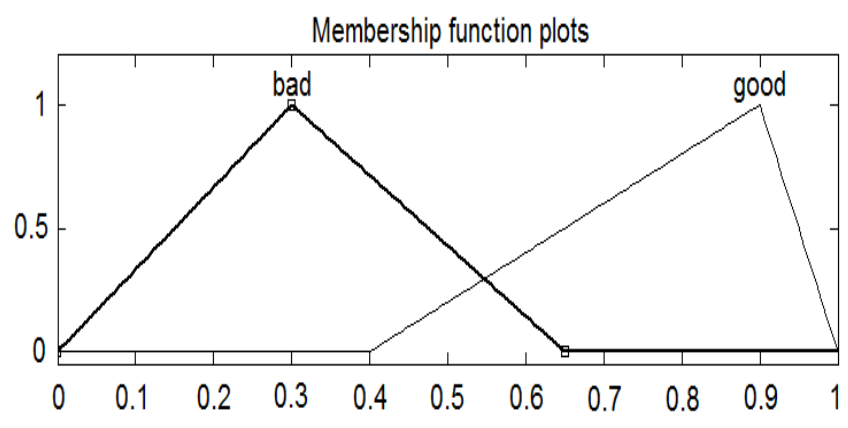

Fig. 5. Representation of the membership functions for the input variable "NC_of_recovered_watermark". 


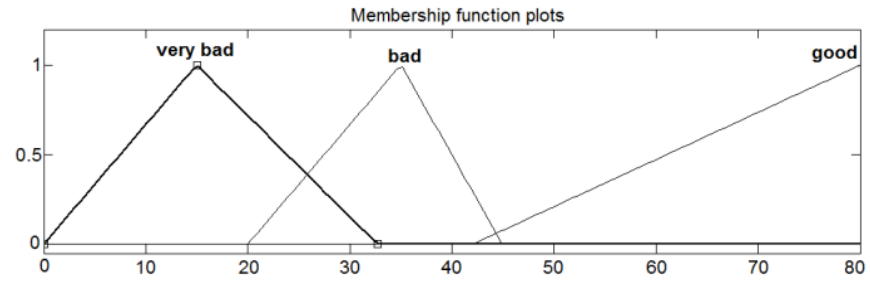

Fig. 6. Representation of the membership functions for the input variable "PSNR_of_watermarked_image".

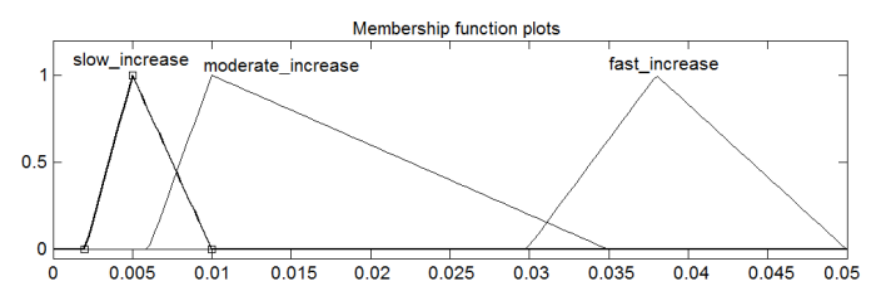

Fig. 7. Representation of the membership functions for the output variable "Embedding_Strength".

While embedding a 64 bits watermark, in every iteration of the embedding process, the embedding strength " $\mathrm{k}$ ", $\mathrm{NC}$ of the recovered watermark and the PSNR of the watermarked image change. Those changes while embedding the watermark in the "Airplane" image are shown in Figure 8 and Figure 9 as an example.

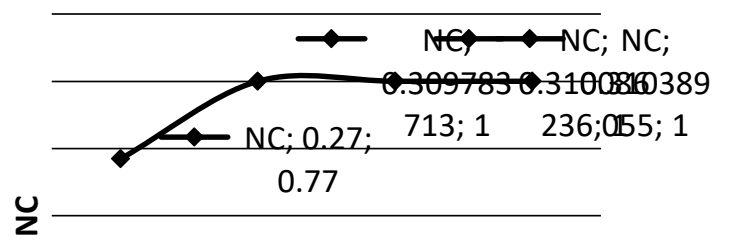

Embedding strength

Fig. 8. Embedding strength and NC while embedding a 64 bits watermark.

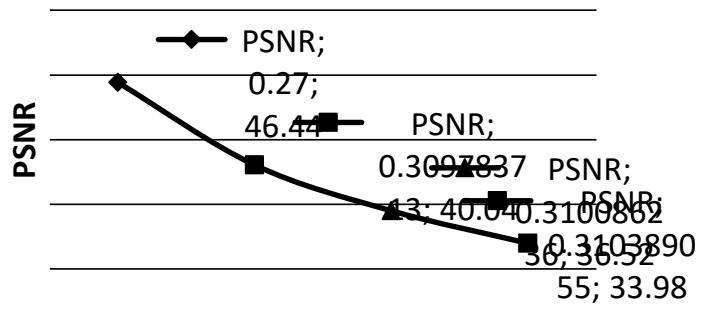

\section{Results and discussion}

We tested our proposed watermarking system by embedding an $8 \times 8$ (64 bits) binary watermarks into 5 different 256x256 gray-level images. The images used in the tests are from ${ }^{[6]}$ and the specific images we used from ${ }^{[6]}$ are "Peppers", "Airplane (F-16)", "Pentagon", "Boat", and "Tank", as shown in Figure 10.

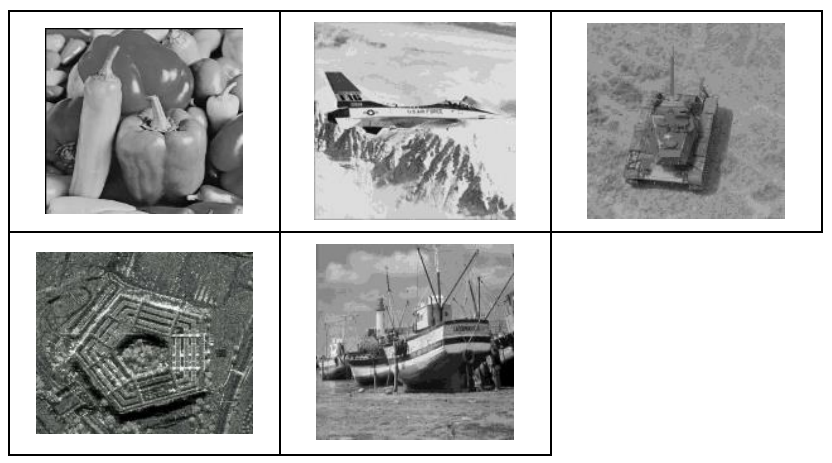

Fig.10. Sample of images used in the tests.

For all the tests we performed in this research, we used the same $8 \times 8$ watermark. We also used the same user defined inputs which are: the counter for the loop is set to 50, the PSNR is set to less or equal to $34 \mathrm{~dB}$, and the initial embedding strength " $\mathrm{k}$ " is set to 0.27 . We tested the proposed system by embedding the binary water mark in the 5 previously mentioned images, and then attacking them with JPEG compression attacks using different JPEG compression Quality Factors. The results of the tests are shown in Table IV. We also compared our proposed system with ${ }^{[7]}$ which is proposed to be robust against lossy compression. We found that even though both systems are robust yet the results from our system shows that our system is more robust than the system in ${ }^{[7]}$ as shown in Table $\mathrm{V}$ which measures the results of the recovered watermarks in Bit Error Rate (BER). Our proposed system calculates the Normalized Cross-correlation (NC), Bit Error Rate (BER) and Peak Signal-to-Noise Ratio (PSNR) as mentioned before and documented in [8].

\section{Embedding strength}




\begin{tabular}{|l|l|l|l|l|l|}
\hline JPEG CQF & Peppers & Airplane & Pentagon & Boat & Tank \\
\hline 90 & 0 & 0 & 0 & 0 & 0 \\
\hline 80 & 0 & 0 & 0 & 0 & 0 \\
\hline 70 & 0 & 0 & 0 & 0 & 0 \\
\hline 60 & 0 & 0 & 0 & 0 & 0 \\
\hline 50 & 0 & 0 & 0 & 0 & 0 \\
\hline 40 & 0 & 0 & 0 & 0 & 0 \\
\hline 30 & 0 & 0.02 & 0.02 & 0.03 & 0 \\
\hline 20 & 0.09 & 0.09 & 0.05 & 0.05 & 0 \\
\hline 10 & 0.16 & 0.23 & 0.13 & 0.09 & 0.06 \\
\hline \multicolumn{5}{|l|}{} \\
\hline Image & Peppers & Airplane & Pentagon & Boat & Tank \\
\hline PSNR(dB) & 33.99 & 33.98 & 34.00 & 33.99 & 33.99 \\
\hline $\begin{array}{l}\text { Embedding } \\
\text { strength }\end{array}$ & 0.31 & 0.31 & 0.31 & 0.31 & 0.31 \\
\hline \# iterations & 4 & 4 & 4 & 4 & 4 \\
\hline $\begin{array}{l}\text { \# fully } \\
\text { recovered } \\
\text { watermarks }\end{array}$ & 7 & 6 & 6 & 6 & 8 \\
\hline
\end{tabular}

In our comparison that we did between our proposed system and the system in ${ }^{[7]}$, the results in Table $\mathrm{V}$ show that under the same JPEG quality factors used with both systems our system is more robust than the system in ${ }^{[7]}$.

TABLE V

\begin{tabular}{|l|l|l|l|l|}
\hline & \multicolumn{2}{|c|}{ BER: PROPOSED SYSTEM } & \multicolumn{2}{c|}{ BER: SYSTEM IN ${ }^{[7]}$} \\
\hline $\begin{array}{c}\text { JPEG } \\
\begin{array}{c}\text { Compression } \\
\text { QF }\end{array}\end{array}$ & Tank & Pentagon & Tank & Pentagon \\
\hline $90 \quad$ & 0 & 0 & 0 & 0 \\
\hline 80 & 0 & 0 & 0 & 0 \\
\hline 70 & 0 & 0 & 0 & 0 \\
\hline 60 & 0 & 0 & 0 & 0 \\
\hline 50 & 0 & 0 & 0 & 0 \\
\hline 40 & 0 & 0 & 0 & 0 \\
\hline 30 & 0 & 0.02 & 1.56 & 4.69 \\
\hline 20 & 0 & 0.05 & 15.62 & 10.94 \\
\hline
\end{tabular}

Table VI shows the PSNRs of the watermarked images. It illustrates that our system gave better results compared to ${ }^{[7]}$ with attacks of QF: 40, 30, and 20. In ${ }^{[2]}$, the researchers found that NSCT requires more time than the Contourlet transform to embed and recover watermarks which might make it not suitable for real time applications. We also found, from our system, that NSCT uses large amount of time to finish its work which makes it good for robust systems but not good for systems that are built for real time embedding and recovering. We tested transforming an image using NSCT to $(\mathrm{n}$ levels $=[1,2,3,4])$, then back again to an image and we used the "Peppers" image for that test, it took 26.7875 seconds to transform and 26.8836 seconds to inverse transform the image. We also used the "Airplane (F-16)" image which took 27.4955 seconds while transforming and 26.9691 seconds to inverse transform the data back to an image. NSCT is not the main reason of why our system consumes too much time, but also because of the number of components that our system is based on which added more to the complexity of the system (SSCDMA, DWT, loop, and fuzzy logic). During performing the experiments, we measured the time that the system took to complete the task, we found that it took 3.99 minutes to embed and 34.2755 seconds to recover the watermark using the "Peppers" image and 4.12 minutes for embedding and 34.3496 seconds for recovering using the "Airplane (F-16)" image and 3.98 minutes for embedding and 34.1531 seconds to recover when using the "Pentagon" image and 3.97 minutes for embedding and 34.3107 seconds for recovering when using the "Boat" image and 3.98 minutes for embedding and 34.3534 seconds for recovering while using the "Tank" image. The system in ${ }^{[7]}$ supports video watermarking. The results showed that our system is good for image watermarking but not suitable yet for using it to watermark videos as ${ }^{[8]}$ states that video watermarking systems should not take heavy computational cost. Nevertheless, using $\mathrm{C}++$ instead of MATLAB in our implementation can speed up the system by a factor of 10 or more (546) times as reported in [10].

TABLE VI

\begin{tabular}{|l|l|l|l|l|}
\hline & \multicolumn{2}{|c|}{$\begin{array}{c}\text { PSNR: PROPOSED } \\
\text { SYSTEM }\end{array}$} & \multicolumn{2}{c|}{ PSNR: SYSTEM IN ${ }^{[7]}$} \\
\hline $\begin{array}{c}\text { JPEG } \\
\begin{array}{c}\text { Compression } \\
\text { QF }\end{array}\end{array}$ & Tank & Pentagon & Tank & Pentagon \\
\hline 90 & 32.97 & 32.71 & 39.33 & 37.57 \\
\hline 80 & 32.77 & 31.90 & 37.08 & 35.73 \\
\hline 70 & 32.68 & 31.47 & 34.77 & 33.88 \\
\hline 60 & 32.48 & 31.04 & 33.14 & 32.40 \\
\hline 50 & 32.24 & 30.68 & 31.47 & 30.89 \\
\hline 40 & 31.94 & 30.25 & 30.07 & 29.46 \\
\hline 30 & 31.48 & 29.67 & 28.97 & 28.37 \\
\hline 20 & 30.86 & 28.73 & 27.85 & 27.35 \\
\hline
\end{tabular}

To better compare our results to the results from the system in ${ }^{[7]}$, a comparison between our and their PSNRs is shown in Figure 11, and another 
comparison between our and their BER is shown in Figure 12.

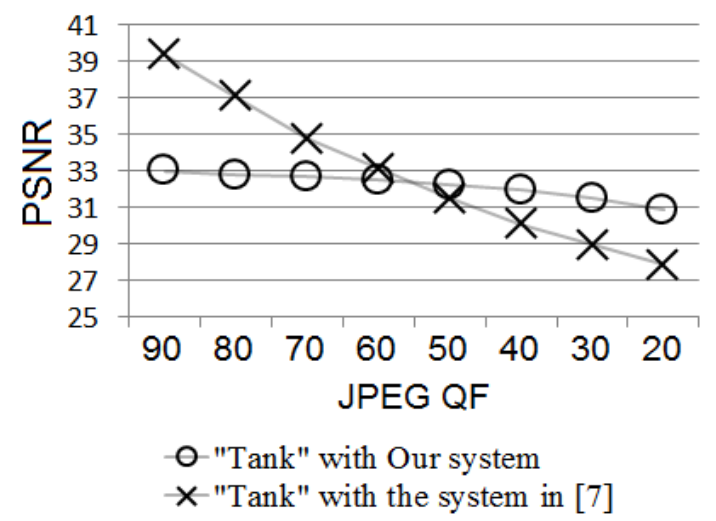

Fig. 11. PSNRs from our system and the system in ${ }^{[7]}$ for "Tank".

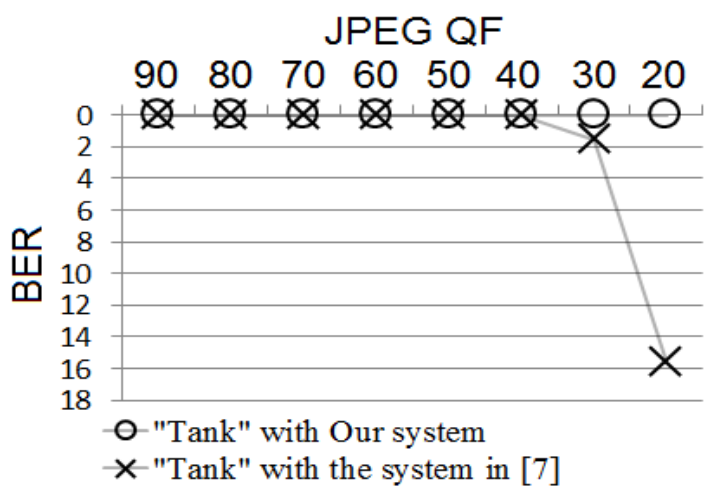

Fig. 12. BERs from our system and the system in ${ }^{[7]}$ for "Tank".

To test how good our system is in embedding watermarks with capacities other than 64bits we took 4 copies of all the 5 images we used in our experiments in this paper and 4 watermarks with various sizes and then we embedded each watermark to one of the 4 copies. The watermark sizes and the JPEG QF in this experiment were chosen to be similar to the ones in the experiment done in ${ }^{[7]}$. In each of the 4 image copies, we only embed one watermark in each copy. Then we compared our results with the results in ${ }^{[7]}$. We used 4 watermarks with capacitates of $51,79,147$ and 292 bits. To get the results for this test, we attacked the 4 copies of each image with JPEG Compression where each of the 4 copies had a different JPEG QF value used with it. The copies were attacked with JPEG QF $=40,65,85$ and 95. The results of this experiment are shown in Table VII, and Table VIII. From the results, we found that in this experiment that our proposed system outperforms the system in ${ }^{[7]}$ only in " 292 bits \& JPEG QF=95". The system in "7] gave better PSNRs than our system, on the other hand, our system gave better BERs than the system in ${ }^{[7]}$. For more investigations of the functions and significance of the various components and parameters in our system, the reader can review the thesis on which this paper is based on ${ }^{[11]}$.

TABLE VII. WATERMARKED IMAGES' PSNRS AFTER TESTING OUR PROPOSED SYSTEM WITH WATERMARKS WITH VARIOUS CAPACITIES

\begin{tabular}{|l|c|c|c|c|}
\hline \multicolumn{1}{|c|}{ Embedded Bits } & 51 & 79 & 147 & 292 \\
\hline Attacked JPEG QF & 40 & 65 & 85 & 95 \\
\hline Peppers & 31.22 & 32.10 & 32.55 & 31.02 \\
\hline Pentagon & 29.69 & 30.29 & 31.73 & 30.98 \\
\hline Airplane & 30.34 & 31.04 & 32.32 & 31.00 \\
\hline Boat & 29.80 & 30.73 & 32.20 & 31.00 \\
\hline Tank & 31.13 & 31.82 & 32.20 & 30.98 \\
\hline System in ${ }^{[7]}$ & 37.96 & 36.40 & 32.73 & 29.72 \\
\hline
\end{tabular}

TABLE VIII. WATERMARKED IMAGES' BERS AFTER TESTING OUR PROPOSED SYSTEM WITH WATERMARKS WITH VARIOUS CAPACITIES

\begin{tabular}{lcccc}
\hline \hline & $\begin{array}{c}51 \text { bits } \\
\text { embedded } \\
\text { attacked } \\
\text { with JPEG } \\
\mathrm{QF}=40\end{array}$ & $\begin{array}{c}\text { 79bits } \\
\text { embedded } \\
\text { attacked } \\
\text { with JPEG } \\
\mathrm{QF}=65\end{array}$ & $\begin{array}{c}\text { 147bits } \\
\text { embedded } \\
\text { attacked } \\
\text { with JPEG } \\
\mathrm{QF}=85\end{array}$ & $\begin{array}{c}\text { 292bits } \\
\text { embedded } \\
\& \\
\text { attacked } \\
\text { with JPEG } \\
\text { QF= 95 }\end{array}$ \\
\hline Peppers & 0 & 0 & 0 & 0 \\
Pentagon & 0 & 0 & 0 & 0 \\
Airplane & 0 & 0 & 0 & 0 \\
Boat & 0 & 0 & 0 & 0.01 \\
Tank & 0 & 0 & 0.01 & 0 \\
System in [7] & 0 & 0 & 0 & 0.34 \\
\hline \hline
\end{tabular}

\section{Conclusion}

This paper proposed a hybrid watermarking system that is NSCT-DWT based using SSCDMA for embedding and recovering and fuzzy logic for automatically choosing the embedding strength. The results of the experiments we did showed that the proposed system is robust against JPEG compression, secure and provide good imperceptibility, although it suffers from being computationally intensive which can be solved by using $\mathrm{C}++$ instead of MATLAB in our implementation.

The results showed that implementing an error correcting code can help the system in recovering corrupted watermarks. The use of SS-CDMA in the system improved the system's security. The fuzzy logic used in the system gave it the ability to find out the embedding strength for each host image automatically. The use of DWT alongside 
NSCT in our system improved its robustness as shown in our results.

\section{REFERENCES}

[1] Jayalakshmi, M., Shabbir N. Merchant, and Uday B. Desai. "Blind watermarking in contourlet domain with improved detection." In Intelligent Information Hiding and Multimedia Signal Processing, 2006. IIH-MSP'06. International Conference on, pp. 449-452. IEEE, 2006.

[2] Gao, Guangyong, Baoqin Cai, Shaowen $\mathrm{Xu}$, and Tao Yan. "Watermark performance contrast between contourlet and nonsubsampled contourlet transform." In Information and Automation (ICIA), 2012 International Conference on, pp. 507-511. IEEE, 2012.

[3] Da Cunha, Arthur L., Jianping Zhou, and Minh N. Do. "The nonsubsampled contourlet transform: theory, design, and applications." Image Processing, IEEE Transactions on 15, no. 10 (2006): 3089-3101.

[4] "Minh N. Do: Software, Nonsubsampled Contourlet Toolbox," [Online]. Available: http://www.ifp.illinois.edu/ minhdo/software/. [Accessed 16 $12014]$.

[5] Shoemaker, Chris. "Hidden bits: A survey of techniques for digital watermarking." Independent study, EER 290 (2002): 1673-1687.
[6] "The USC-SIPI Image Database," University of Southern California, Viterbi School of Engineering, [Online]. Available: http://sipi.usc.edu/database/. [Accessed 53 2014].

[7] Chen, Qing, Henri Maître, and Qiu-ping Deng. "Reliable information embedding for image/video in the presence of lossy compression." Signal Processing: Image Communication 27, no. 1 (2012): 66-74.

[8] Lee, Min-Jeong, Dong-Hyuck Im, Hae-Yeoun Lee, Kyung-Su Kim, and Heung-Kyu Lee. "Real-time video watermarking system on the compressed domain for high-definition video contents: Practical issues." Digital Signal Processing 22, no. 1 (2012): 190-198.

[9] Matlab Documentation, Version 7.11, release 2010b, The MathWorks Inc., 2010.

[10] Andrews, T., "Computation time comparison between Matlab and C++ using launch windows," Aerospace Engineering, California Polytech State University: San Luis Obispo, pp. 1-6, Jun. 2012.

[11] B. Albarakati, "A Hybrid Transform Technique for Image Watermarking", Master thesis in computer science in the faculty of Computing and Information Technology, King Abdulaziz University, Jeddah, Saudi Arabia JUNE 2014. 


\title{
تضمين محكوم بمنطق ضبابي للعلامات المائية في الصورعلى اساس تقنية محول ثنائي
}

\author{
بندر محمد البركاتي، د. عبدالله أحمد باسهيل، د. جبرائيل الأمين أبوسمره \\ كلبة الحاسبات وتقنية الدعلومات، جامعة الدلك عبدالعزيز \\ جذة، الدملكة العربية السعودية
}

المستخلص. تقدم هذه الورقة طريقة جديدة لعمل علامة مائية باستخدام تحويلات هجينة لصورة، والتي تهدف إلى أن تكون متينة جدا ضد الهجمات. كما تهذف هذه الطريقة إلى تقليل كمية التشويه الناشئ من تضمين العلامة المائية إلى أقصى حد ممكن، ويكون لها سعة جيدة. يستخدم النظام المقترح طريقة هجينة لعمل علامة مائية تعتمد على تحويل كفافي بدون عينات فرعية، وعلى تحويل المويجات المقطعة. إضافة إلى ذلك، فان النظام المقترح يستخدم المنطق الضبابي للاختبار التلقائي لقوة العلامة المائية المضمنة. علاوة على ذلك، بستخدم هذا النظام طريقة الانتشار الطيفي متعدد الوصول بالكود المنقسم، لتضمين واسترداد العلامة المائية بعد تحويل الصورة. ولتحسين استرداد العلامات المائية، يستخدم النظام الوفرة على مستوى عال من في عملية التضمين، والتي تسمح باستخدام رمز تصحيح خطأ قوي في عملية الاسترداد. ينم استخدام المنطق الضبابي لمساعدة النظام في إنتاج صور معلمة مائيا، والتي تحافظ بجودتها، ولم تتغير بشكل كبير بعد تضمين العلامة المائية. وقد أجريت تجارب لقياس جودة النظام المقترح باستخدام هجمات ضغط جيه-بيغ. و أظهرت النتائج أن النظام المقترح منين، ولديه سعة جيدة، وغير محسوس، غير أنه معقد حسابيا.

الكلمات الدفتاحية : العلامة المائية، معالجة الصور، تحويلات المويجات المقطعة، التحويل الكفافي بدون عينات فرعية، المنطق الضبابي، رمز تصحيح الخطأ، الانتشار الطيفي. 